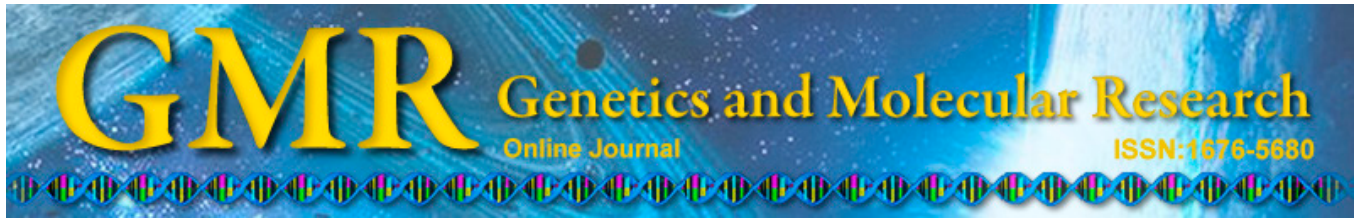

\title{
Genetic diversity and taxonomic status of Pinus tabulaeformis f. shekanensis revealed by ISSR markers
}

\author{
Z.-H. Liu, Q. Xie and Z.-Q. Li \\ College of Forestry, Northwest A\&F University, Yangling, China \\ Corresponding author: Z.-Q. Li \\ E-mail: lizhouqi@nwsuaf.edu.cn
}

Genet. Mol. Res. 14 (1): 1034-1043 (2015)

Received January 14, 2014

Accepted July 2, 2014

Published February 6, 2015

DOI http://dx.doi.org/10.4238/2015.February.6.7

\begin{abstract}
Pinus tabulaeformis f. shekanensis is a rare taxon endemic in the Ziwuling Loess Plateau, of which only one population is known. Inter-simple sequence repeat molecular markers were employed to compare the taxon's genetic diversity with its 4 nearest wild relatives ( $P$. tabulaeformis, $P$. tabulaeformis var. mukdensis, $P$. massoniana, and $P$. henryi) to assess the taxonomic status of $P$. tabulaeformis f. shekanensis. Inter-simple sequence repeat marker data revealed higher genetic diversity in the $P$. tabulaeformis f. shekanensis population than in the other populations. Population genetic analysis (neighbor-joining cluster analysis, principal coordinate analysis, and structure clustering) revealed that $P$. tabulaeformis f. shekanensis and $P$. tabulaeformis are likely conspecific (the former may be a variety of the latter). Strategies are also proposed for the conservation of $P$. tabulaeformis f. shekanensis.
\end{abstract}

Key words: Narrow endemic; Inter-simple sequence repeat; Genetic diversity conservation; Pinus tabulaeformis f. shekanensis; Taxonomic status 


\section{INTRODUCTION}

Pinus tabulaeformis f. shekanensis, a pine taxon, is morphologically similar to $P$. tabulaeformis Carr. and is distributed in Fuxian County of Shaanxi Province in China with a total area of approximately $337.3 \mathrm{ha}$ (Zhu, 1987). Compared to P. tabulaeformis, P. tabulaeformis f. shekanensis has several advantages such as high-stress tolerance, wide adaptability, fast-growth, straight stem, and good natural pruning (Le, 1957; Zhu, 1987; Zhao et al., 2009). It is recognized as a valuable genetic resource in regions of Loess Plateau of northwest China and should be protected from overexploitation. Currently, the taxonomic status of $P$. tabulaeformis $\mathrm{f}$. shekanensis is disputed in academic fields and its genetic diversity is not well understood, limiting systemic research and efficient protective programs.

P. tabulaeformis f. shekanensis, first described by Le (1957), has been classified in various taxonomic groups over the last half century. It was initially considered to be a form of P. tabuliformis by Le (1957), then synonymized with P. tabuliformis (Zhu, 1987), and then treated as a variety of $P$. tabuliformis (Liu et al., 2013), and considered to be a distinct species in our former study (Liu ZH, Xie Q and Li ZQ, unpublished results). Recently, the taxon was classified as a form of P. tabuliformis (Zhao et al., 2009; Xie et al., 2013; Li, 2013; Li et al., 2013). Conceptually, form is regarded as sporadic variant distinguished by a single-linked character (Jones and Luchsinger, 1986; Gurcharan, 2004). However, the form concept is restrictively applied to $P$. tabulaeformis f. shekanensis because of it owes a large population and many variations (needle, cone, bark, stem taper, branch angle, resin canal, and wood texture, etc.) (Zhu, 1987; Xie et al., 2013; Li, 2013; Li et al., 2013).

Understanding genetic variation within and between populations is essential for establishing effective and efficient conservation programs aimed at preserving rare plant species (Hogbin and Peakall, 1999). Processes such as genetic drift, diversity loss resulting from bottlenecks, and genetic differentiation can be addressed through studies based on genetic markers (Petit et al., 1998). Furthermore, molecular markers are very useful for studying genetic variation in rare, threatened, and endangered species (Wang and Ruan, 2012; Wang et al., 2012), and thus any results obtained concerning the genetic diversity of $P$. tabulaeformis f. shekanensis may be of interest for its management and conservation.

In this study, we used a technique based on DNA fingerprinting known as the intersimple sequence repeat (ISSR) method (Zietkiewicz et al., 1994). ISSR refers to the amplification of a DNA region located between 2 microsatellite loci; this technique combines the advantages of random amplified polymorphic DNA markers with high polymorphism and reliability of microsatellites. This marker type has been successfully used for cultivar identification (Assefa et al., 2003; Wang et al., 2013), hybrid species discrimination (Wolfe and Randle, 2001; Chung et al., 2013), and genetic map construction, as well as intra- and interspecies genetic diversity and relationship determination in closely related taxa (Bodo Slota and Porter, 2006; Galván et al., 2010; Li et al., 2011). In this study, we examined genetic variation in P. tabulaeformis f. shekanensis compared with its nearest wild relatives to assess taxonomic status of $P$. tabulaeformis f. shekanensis and to propose new conservation policies for this rare taxon.

\section{MATERIAL AND METHODS}

\section{Plant materials}

Five taxa of the Pinus were analyzed in this study including P. tabulaeformis $\mathrm{f}$. 
shekanensis, P.tabulaeformis, P. tabulaeformis var. mukdensis (the variety of P. tabulaeformis), and $P$. henryi and $P$. massoniana (relatives of $P$. tabulaeformis). The location of taxa and the accession numbers sampled are shown in Table 1 and Figure 1. Fresh needles were sampled from individual adult trees from each population. Distances between sampled trees were from 50-100 m depending on the population size. This was done in an effort to ensure that the sample trees were representative of their populations. To avoid degradation of plant tissues, all samples were labeled and stored in sealed bags with silica gel as described by Sytsma et al. (1993) until DNA extraction.

Table 1. Locations of the sampled Pinus taxa and the sampled number (N).

\begin{tabular}{lcllrr}
\hline Taxa & Code & Locality & N & Latitude $\left({ }^{\circ} \mathrm{N}\right) /$ Longitude $\left({ }^{\circ} \mathrm{E}\right)$ & Elevation $(\mathrm{m})$ \\
\hline P. tabulaeformis f. shekanensis & $\mathrm{C}$ & Fuxian, Shaanxi & 50 & $35.998 / 108.690$ & 1316 \\
P. tabulaeformis & $\mathrm{Y}$ & Huanglong, Shaanxi & 30 & $35.632 / 109.772$ & 1127 \\
P. tabulaeformis var. mukdensis & $\mathrm{H}$ & Anshan, Liaoning & 30 & $40.960 / 123.147$ & 294 \\
P. massoniana & $\mathrm{M}$ & Yangxian, Shaanxi & 30 & $33.326 / 107.624$ & 722 \\
P. henryi & $\mathrm{B}$ & Nanzheng, Shaaxi & 30 & $32.857 / 106.586$ & 1254 \\
\hline
\end{tabular}

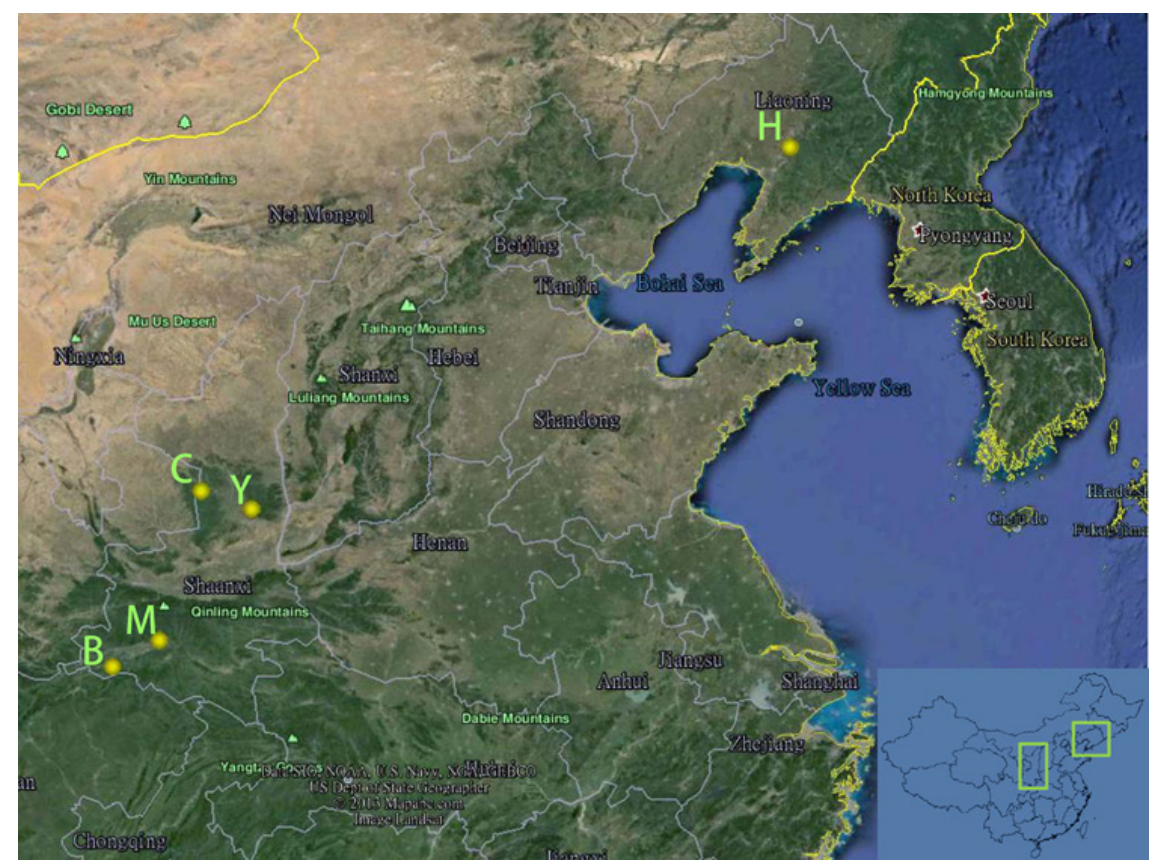

Figure 1. Geographic distribution of Pinus taxa sampled for ISSR analysis.

\section{DNA extraction and ISSR-PCR amplification}

Total genomic DNA was extracted from silica gel-dried needles of each plant using a DNA secure Plant kit (TIANGEN Biotech Co., Ltd., Beijing, China). Quality of the total DNA was verified by gel electrophoresis (1\% agarose gel) and quantified using a BioPhotometer plus (Eppendorf, Hamburg, Germany). DNA samples were stored at $-20^{\circ} \mathrm{C}$ until ISSR amplification. 
A subset of 12 primers (Table 2) chosen from 100 primers (UBC primer set No. 9, Biotechnology Laboratory, University of British Columbia), which yielded bright and discernible bands in 2 random samples of each taxon, were used to analyze all 170 samples. ISSR amplifications were performed in a $20-\mu \mathrm{L}$ volume containing $1 \mathrm{X}$ PCR buffer, $40 \mathrm{ng}$ genomic DNA, $0.2 \mathrm{mM}$ dNTPs, $0.2 \mathrm{mM} \mathrm{Mg}^{2+}, 0.4 \mathrm{mM}$ primers, and $1 \mathrm{U}$ Taq DNA polymerase. The cycle program included an initial 5-min denaturation at $94^{\circ} \mathrm{C}$, followed by 45 cycles of $30 \mathrm{~s}$ at $94^{\circ} \mathrm{C}, 45 \mathrm{~s}$ at $58^{\circ} \mathrm{C}$, and $2 \mathrm{~min}$ at $72^{\circ} \mathrm{C}$, with a 10 -min final extension at $72^{\circ} \mathrm{C}$. The amplified products were separated on $2 \%$ agarose gels buffered with $1 \mathrm{X}$ Tris-borate-EDTA. PCR products were detected using the Image Analysis software for gel documentation (Quantity on Version 3.6) after staining with ethidium bromide.

\section{Data analysis}

Amplified fragments with the same mobility according to their molecular weights (bp) were scored using a binary code as present (1) or absent (0). Only consistently reproducible bands were scored, while smeared and weak bands were excluded. For comparisons, the intrataxa genetic diversity was inferred using POPGENE 1.32 (Yeh et al., 1999). The parameters estimated were percentage of polymorphic loci (PPB), total gene diversity (Smith et al., 1997), Shannon diversity index (I) (Lewontin, 1972), Nei's unbiased gene diversity $(H)$ (Nei, 1973), and the relative magnitude of genetic differentiation among populations $\left(G_{\mathrm{ST}}\right)(\mathrm{Nei}, 1973)$. The 1/0 matrix was transformed into a Nei and Li genetic distance matrix using FreeTree (Hampl et al., 2001). The phenograms using the neighbor-joining (NJ) method was conducted with the MEGA 4.0 software (Tamura et al., 2007). Genetic divergence between taxa was investigated using Nei's unbiased genetic distances and genetic identities (Nei, 1978). Nei's unbiased genetic distances were used to construct NJ tree by MEGA 4.0 (Tamura et al., 2007). Analysis of molecular variance was conducted to estimate variance components at several hierarchical levels, partitioning the variation among populations and among individuals within populations, using the GenAlEx v6.5 program (Peakall and Smouse, 2012). In addition, principal co-ordinate analysis (PCoA) in GenAlEx 6.5 was employed to further examine the genetic relationships among detected taxa based on the same ISSR data.

Finally, Bayesian analysis of ISSR population structure was performed on the entire data set using the STRUCTURE 2.3.2 program (Pritchard et al., 2000) to detect population structure and estimate the number of populations $(K)$ in a sample as well as to assign individuals to 1 or more of these populations $(K)$. The number of genetically distinct clusters $(K)$ was set to vary from 1-5. The model was run for 10 independent simulations for each $K$, using a burn-in length of 50,000 and a run length of 100,000 iterations. The most likely number of clusters was estimated according to the model value $(\Delta K)$ based on the second-order rate of change, with respect to $K$, of the likelihood function, following the procedure described by Evanno et al. (2005).

\section{RESULTS}

\section{Genetic diversity}

Twelve primers, including UBC818, UBC820, UBC825, UBC826, UBC829, UBC846, UBC847, UBC849, UBC850, UBC856, UBC857, and UBC859, were used based on their good polymorphism, and a total of 126 bands were amplified using these primers se- 
lected from 170 individuals of the 5 Pinus taxa (approximately 10.5 bands per primer) (Table 2). A total of 123 bands were polymorphic (97.62\%) among the 170 individuals; i.e., the PPB among these taxa was $97.62 \%$. At the taxa level, the PPB per taxon ranged from 70.63$84.13 \%$, with an average of $74.13 \%$. The mean expected $H$ was estimated to be 0.2187 within species and 0.2764 at the inter-taxa level, assuming the Hardy-Weinberg equilibrium. The $I$ ranged from 0.3041-0.3685, with an average of 0.3386 at the taxa level or 0.4296 at the intertaxa level. As shown in Table 3, P. tabulaeformis f. shekanensis showed the greatest level of variability (PPB: $84.13 \%, H: 0.2373$, and $I: 0.3685$ ), whereas the $P$. massoniana exhibits the lowest level of variability (PPB: $69.05 \%, H: 0.1962$, and $I: 0.3041$ ).

Table 2. ISSR primers used in this study, together with the amplified results as number of total bands (TB), number of polymorphic bands (PB), and percentage of polymorphic bands (PPB).

\begin{tabular}{lcccc}
\hline Primer & Sequence $\left(5^{\prime} \rightarrow 3^{\prime}\right)$ & TB & PB & PPB (\%) \\
\hline UBC818 & $(\mathrm{CA})_{8} \mathrm{G}$ & 14 & 14 & 100 \\
UBC820 & $(\mathrm{GT})_{8} \mathrm{C}$ & 10 & 10 & 100 \\
UBC825 & $(\mathrm{AC})_{8} \mathrm{~T}$ & 8 & 8 & 100 \\
UBC826 & $(\mathrm{AC})_{8} \mathrm{C}$ & 9 & 9 & 100 \\
UBC829 & $(\mathrm{TG})_{8} \mathrm{C}$ & 11 & 10 & 90.91 \\
UBC846 & $(\mathrm{TG})_{8} \mathrm{C}$ & 11 & 11 & 100 \\
UBC847 & $(\mathrm{CA})_{8} \mathrm{RC}$ & 9 & 9 & 87.50 \\
UBC849 & $(\mathrm{GT})_{8} \mathrm{YA}$ & 8 & 7 & 88.89 \\
UBC850 & $(\mathrm{GT})_{8} \mathrm{YC}$ & 9 & 8 & 100 \\
UBC856 & $(\mathrm{AC})_{8} \mathrm{YA}$ & 17 & 17 & 100 \\
UBC857 & $(\mathrm{AC})_{8} \mathrm{YG}$ & 15 & 15 & 97.62 \\
UBC859 & $(\mathrm{TG})_{8} \mathrm{RC}$ & 5 & 5 & - \\
Average & - & 10.50 & 10.25 & \\
Total & - & 126 & 123 & \\
\hline Yol & & & &
\end{tabular}

$\mathrm{Y}=(\mathrm{C}, \mathrm{T}) ; \mathrm{R}=(\mathrm{A}, \mathrm{G})$.

Table 3. Within population genetic diversity of Pinus taxa sampled populations based on ISSR data.

\begin{tabular}{lccccc}
\hline Population & Sample size & No. of PB & PPB (\%) & $H(\mathrm{SE})$ & $I(\mathrm{SE})$ \\
\hline P. tabulaeformis f. shekanensis & 50 & 106 & 84.13 & $0.2373(0.176)$ & $0.3685(0.240)$ \\
P. tabulaeformis & 30 & 90 & 71.43 & $0.2197(0.186)$ & $0.3367(0.262)$ \\
P. tabulaeformis var. mukdensis & 30 & 92 & 73.02 & $0.2116(0.166)$ & $0.3320(0.240)$ \\
P. massoniana & 30 & 87 & 69.05 & $0.1962(0.185)$ & $0.3041(0.260)$ \\
P. henryi & 30 & 92 & 73.02 & $0.2285(0.183)$ & $0.3518(0.254)$ \\
Average & 34 & 93.8 & 74.13 & 0.2187 & 0.3386 \\
Taxa & 170 & 123 & 97.62 & $0.2764(0.154)$ & $0.4296(0.198)$ \\
\hline
\end{tabular}

The genetic differentiation coefficient obtained with POPGENE $\left(G_{\mathrm{ST}}\right)$ was 0.2484 , thus leaving $75.16 \%$ of the total genetic variation harbored within the populations. This was consistent with the results of analysis of molecular variance, which detected the highest genetic variation within the population (75\%), while between-taxa variation was only $25 \%$ (Table 4 ).

Table 4. Analyses of molecular variance (AMOVA) for Pinus taxa by ISSR.

\begin{tabular}{lrcccc}
\hline Source of variation & d.f. & Sum of squares & Variance component & Percent of variance & P value \\
\hline Within population & 165 & 2577.500 & 15.621 & $75.0 \%$ & $<0.01$ \\
Between taxa & 4 & 770.265 & 5.277 & $25.0 \%$ & $100.0 \%$ \\
Total & 169 & 3347.765 & 20.899 & $<.01$ \\
\hline
\end{tabular}




\section{Cluster analysis and PCoA}

To assess the taxonomic status of $P$. tabulaeformis f. shekanensis, NJ cluster analyses for all individuals (Figure 2A) and populations (Figure 2B) of the Pinus taxa were performed. Samples of $P$. tabulaeformis f. shekanensis (C), P. tabulaeformis (Y), and P. tabulaeformis var. mukdensis $(\mathrm{H})$ clustered together, while samples of the other 2 Pinus taxa clustered within 2 well-differentiated groups in the NJ dendrogram (Figure 2A). This confirmed the grouping of individuals within their own taxonomic range. P. massoniana (M) appeared to be the most genetically differentiated. P. henryi (B) occupied an intermediate position, while $P$. tabulaeformis $\mathrm{f}$. shekanensis $(\mathrm{C})$ and $P$. tabulaeformis $(\mathrm{Y})$ were the most closely related.

A

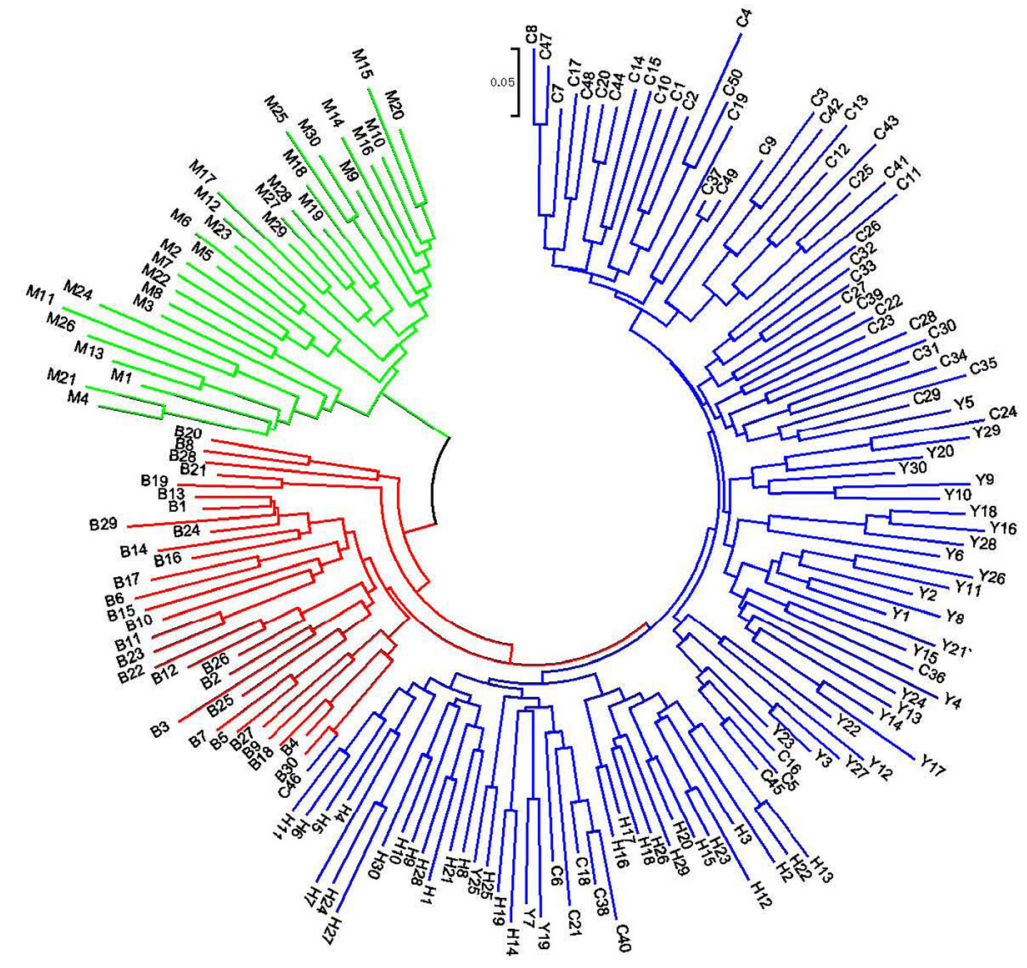

B

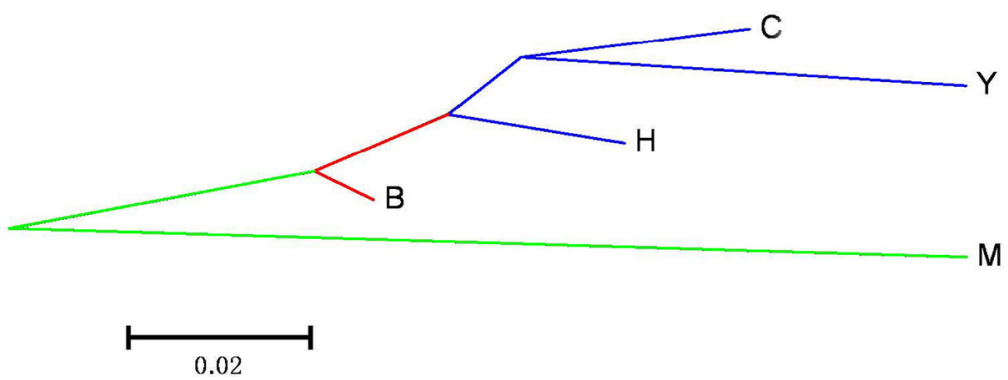

Figure 2. Dendrogram for all individuals (A) and populations (B) of Pinus taxa using neighbor-joining method. 
PCoA was performed to provide a spatial representation of the relative genetic distances among individuals and to determine the consistency of differentiation among taxa defined by cluster analysis. The first 2 principal components explained 38.97 and $17.02 \%$ of the total variation, respectively, while $70.17 \%$ was explained by the first 3 components (Figure 3). The first principal separated most individuals of $P$. tabulaeformis f. shekanensis (C), $P$. tabulaeformis $(\mathrm{Y})$, and P. tabulaeformis var. mukdensis $(\mathrm{H})$ from the individuals of other 2 taxa. The second principal coordinate separated individuals of P. massoniana (M) from the individuals of other 4 taxa. The results of PCoA indicated that $P$. tabulaeformis $\mathrm{f}$. shekanensis (C), P. tabulaeformis (Y), and P. tabulaeformis var. mukdensis $(\mathrm{H})$ are in a close taxon.

\section{Principal Coordinates (PCoA)}

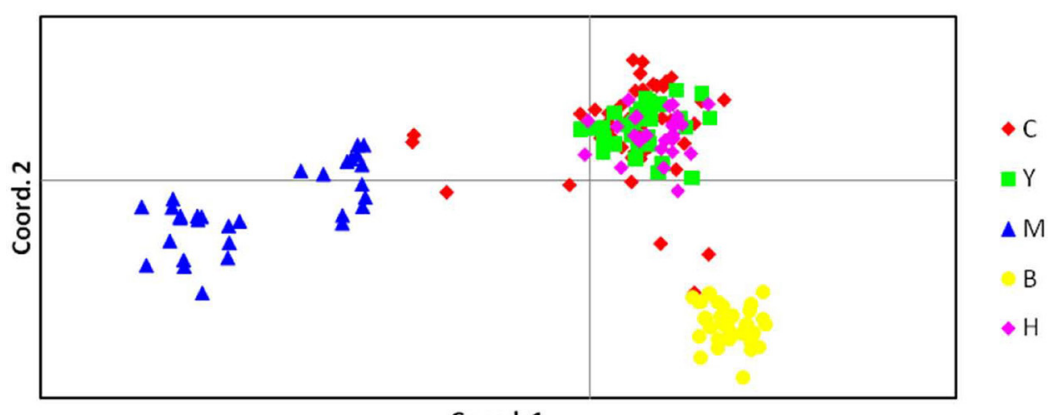

Figure 3. Two-dimensional plot of the principal coordinate analysis (PCoA) of ISSR data showing the clustering of populations of Pinus taxa. The first and second principal coordinates account for 38.97 and 17.02\% of total variation, respectively.

\section{Structure analysis}

In the ISSR admixture analysis using STRUCTURE (Figure 4), the highest likelihood of the data was obtained when samples were clustered into 3 groups $(K=3)$. For the 5 Pinus taxa dataset, the 3 clusters corresponded to the combination of $P$. tabulaeformis $\mathrm{f}$. shekanensis (C)-P. tabulaeformis (Y)-P. tabulaeformis var. mukdensis (H) ('blue' cluster), the $P$. massoniana (M, 'green' cluster), and to the $P$. henryi (B 'red' cluster), further indicating that $P$. tabulaeformis $\mathrm{f}$. shekanensis $(\mathrm{C})$, P. tabulaeformis $(\mathrm{Y})$, and P. tabulaeformis var. mukdensis $(\mathrm{H})$ were conspecific. These results agreed with the PCoA and NJ cluster results.

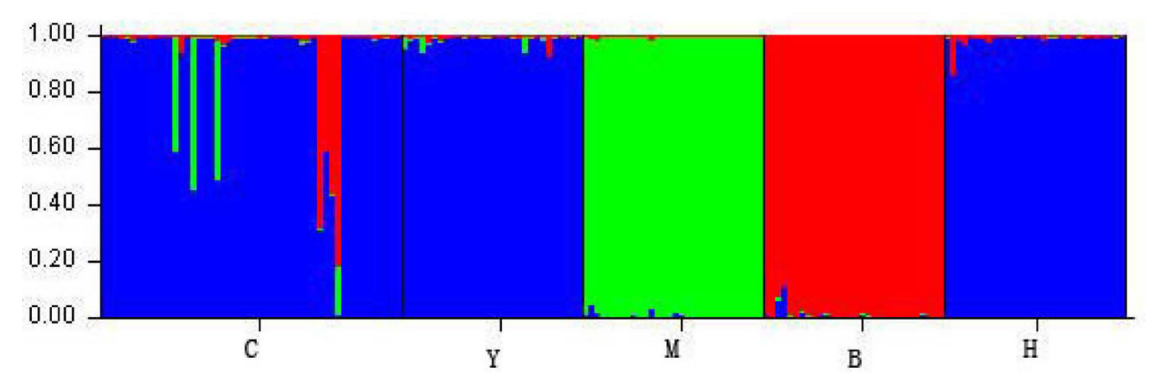

Figure 4. Genetic relationships among the Pinus taxa estimated using STRUCTURE program based on ISSR data. The model with $K=3$ showed the highest $\Delta K$ value. 


\section{DISCUSSION}

\section{Genetic diversity}

In this study, ISSR markers were used to assess the genetic diversity of 5 Pinus taxa. The results show that there are approximately 123 polymorphic bands $(97.62 \%)$, with a distribution that was consistent with Hardy-Weinberg equilibrium $(\mathrm{P}>0.01)$. The average Nei's gene diversity and Shannon's information index were $0.2764 \pm 0.154$ and $0.4296 \pm 0.198$, respectively, at the taxa level (Table 3). These results indicate a moderate level of genetic diversity at the taxa or population level. The observed levels of genetic diversity and the number of polymorphic loci within populations can be explained by the allogamous mating system and anemophilous pollination of Pinus, which may prevent loss of alleles and genetic diversity through genetic drift (De-Lucas et al., 2009; Liu, 2012).

Numerous examples in previous studies showed that species with a small geographic range generally maintain less genetic diversity than geographically widespread species (Gitzendanner and Soltis, 2000; Wu et al., 2004; Zheng et al., 2012); however, our data suggest that the taxa restricted to narrow populations ( $P$. tabulaeformis $\mathrm{f}$. shekanensis) were more diverse than $P$. tabulaeformis, a species that is widely distributed. One possible explanation is that sample size was larger, and thus we were able to assign significance to the trend, indicating higher levels of diversity in this taxon (Zhang et al., 2006). The $G_{\mathrm{ST}}$ and $N_{\mathrm{m}}$ of these 5 taxa were 0.2484 and 1.7894 , respectively, indicating that gene flow occurs at both the intertaxa and intra-taxa levels. This result is also well fitted to the allogamous mating system and anemophilous pollination of Pinus.

\section{Taxonomic status of $\boldsymbol{P}$. tabulaeformis f. shekanensis}

The ISSR data clearly suggested that $P$. tabulaeformis f. shekanensis and P. tabulaeformis were conspecific. First, Nei's genetic identity between $P$. tabulaeformis f. shekanensis and $P$. tabulaeformis were high, with an average of 0.9578 , which is within the range of conspecific populations (van der Bank, 2001). Second, NJ cluster analysis as well as PCoA indicated that $P$. tabulaeformis $\mathrm{f}$. shekanensis clustered closely with $P$. tabulaeformis, which consistently indicated their taxonomic status. Third, most notably, the STRUCTURE also clustered $P$. tabulaeformis $\mathrm{f}$. shekanensis with $P$. tabulaeformis, strongly suggesting that the 2 taxa should be merged into 1 species, $P$. tabulaeformis.

In addition, there were stable differences between $P$. tabulaeformis $\mathrm{f}$. shekanensis and $P$. tabuliformis based on morphological and biochemical studies. Compared to P. tabuliformis, $P$. tabulaeformis f. shekanensis has a wider branch angle and stem taper, thinner and shallow crack bark, smaller cones and pollen grain, and less and smaller resin duct in the stem and needle (Zhu, 1987; Zhao et al., 2009; Liu et al., 2013). Xie et al. (2013) also found 14 highly significant differences between cones and seeds of the 2 taxa in a comparison of 24 morphological traits. Furthermore, P. tabulaeformis f. shekanensis exhibited a diagnostic karyotype with diacritic satellite positions on their chromosomes ( $\mathrm{Li}, 2013)$. Wood anatomical characteristics (e.g., number of secretory cells in the resin duct, thickness of inner wall of ray tracheids, number of uniseriate wing cells in fusiform ray), and physio-biochemical traits (chlorophyll and protein contents, peroxidase isozymes) (Li et al., 2013; Li, 2013) congruously revealed the differences between P. tabulaeformis f. shekanensis and P. tabuliformis. 
Therefore, our morphological, biochemical, karyotype, and genetic data indicate that $P$. tabulaeformis f. shekanensis should be considered a variety of $P$. tabuliformis.

\section{Conservation implications}

P. tabulaeformis f. shekanensis is protected by regional law (Zhao et al., 2009). The total distribution of this taxon includes 1 population in an area of approximately 337.3 ha (Zhu, 1987). Despite its narrow distribution, our ISSR data suggested that $P$. tabulaeformis f. shekanensis, although not genetically impoverished, is not free of threat. In fact, a single catastrophic event may lead to its extinction and thus it is very important to establish practical guidelines for its in situ as well as ex situ conservation.

The present ISSR data suggest that for the effective ex situ conservation of the genetic diversity observed in P. tabulaeformis f. shekanensis through the use of a seed bank, the following sampling strategies should be favored: 1) sampling of as many individuals as possible within the population and 2) collecting 1 or a few cones from each individual; this approach will efficiently recover most of the allelic diversity present in the seeds without reducing the number of propagules, as this may alter the chance of seed germination and establishment within populations.

\section{ACKNOWLEDGMENTS}

We thank Kun Yang and Yuan-Hui Liu for sample collection, and Long Li, Lei Xue, and Zang-fu Jin for assistance with the ISSR analysis. Research supported by the National Natural Science Foundation of China (Grant \#30972382).

\section{REFERENCES}

Assefa K, Merker A and Tefera H (2003). Inter-simple sequence repeat (ISSR) analysis of genetic diversity in tef (Eragrostis tef (Zucc.) Trotter). Hereditas 139: 174-183.

Bodo Slota TA and Porter DM (2006). Genetic variation within and between Iliamna corei and Iliamna remota (Malvaceae): Implications for species delimitation. Bot. J. Linn. Soc. 151: 345-354.

Chung MY, Chung JM, López-Pujol J, Park SJ, et al. (2013). Genetic diversity in three species of Forsythia (Oleaceae) endemic to Korea: Implications for population history, taxonomy, and conservation. Biochem. Syst. Ecol. 47: 80-92.

De-Lucas AI, González-Martínez SC, Vendramin GG, Hidalgo E, et al. (2009). Spatial genetic structure in continuous and fragmented populations of Pinus pinaster Aiton. Mol. Ecol. 18: 4564-4576.

Evanno G, Regnaut S and Goudet J (2005). Detecting the number of clusters of individuals using the software STRUCTURE: a simulation study. Mol. Ecol. 14: 2611-2620.

Galván MZ, Lanteri AA, Menéndez Sevillano MC and Balatti PA (2010). Molecular characterisation of wild populations and landraces of common bean from northwestern Argentina. Plant Biosyst. 144: 365-372.

Gitzendanner MA and Soltis PS (2000). Patterns of genetic variation in rare and widespread plant congeners. Am. J. Bot. 87: 783-792.

Gurcharan S (2004). Plant Systematics: An Integrated Approach. Science Publishers Press, New York.

Hampl V, Pavlícek A and Flegr J (2001). Construction and bootstrap analysis of DNA fingerprinting-based phylogenetic trees with the freeware program FreeTree: application to trichomonad parasites. Int. J. Syst. Evol. Microbiol. 51: 731-735.

Hogbin PM and Peakall R (1999). Evaluation of the contribution of genetic research to the management of the endangered plant Zieria prostrate. Conserv. Biol. 13: 514-522.

Jones SB and Luchsinger AE (1986). Plant systematic. McGraw-Hill, New York.

Le TY (1957). The Shannxi-Gansu-Ningxia Basin Fora. Chinese Forestry Publishing House Press, Beijing.

Lewontin RC (1972). Apportionment of human diversity. Evol. Biol. 6: 381-398. 
Li L (2013). Comparison in morphology anatomy and karyotype between Pinus tabulaeformis f. shekanensis and $P$. abulaeformis. Master's thesis, Northwest A\&F University, Yangling.

Li L, Xie Q, Li ZQ and Liu ZH (2013). Studies on comparative anatomy of Pinus tabulaeformis f. shekanensis and Pinus tabulaeformis. J. Northeast For. Univ. 12: 60-63.

Li S, Hu K, Guo J, Yang XL, et at. (2011). Genetic diversity and relationship of Fritillaria thunbergii Miq. landraces and related taxa. Biochem. Syst. Ecol. 39: 725-731.

Liu ZH, Xie Q and Li ZQ (2013). Taxonomical status of Pinus tabulaeformis f. shekanensis based on morphological characteristics of pollen grain under SEM. J. Northwest For. Univ. 2: 61-65.

Liu ZL, Cheng C and Li JF (2012). High genetic differentiation in natural populations of Pinus henryi and Pinus tabuliformis as revealed by nuclear microsatellites. Biochem. Syst. Ecol. 42: 1-9.

Nei M (1973). Analysis of gene diversity in subdivided populations. Proc. Natl. Acad. Sci. U. S. A. 70: 3321-3323.

Nei M (1978). Estimation of average heterozygosity and genetic distance from a small number of individuals. Genetics 89: 583-590.

Peakall R and Smouse PE (2012). GenAlEx 6.5: genetic analysis in Excel. Population genetic software for teaching and research - an update. Bioinformtics 28: 2537-2539.

Petit RJ, El Mousadik A and Pons O (1998). Identifying populations for conservation on the basis of genetic markers. Conserv. Biol. 12: 844-855.

Pritchard JK, Stephens M and Donnelly P (2000). Inference of population structure using multilocus genotype data. Genetics 155: 945-959.

Smith JSC, Chin ECL, Shu H, Smith OS, et al. (1997). An evaluation of the utility of SSR loci as molecular markers in maize (Zea mays L.): comparison with data from RFLPs and pedigree. Theor. Appl. Genet. 95: 163-173.

Sytsma KJ, Givnish TJ, Smith JF and Hain WJ (1993). Collection and storage of land plant samples for macromolecular comparisons. Methods Enzymol. 224: 23-37.

Tamura K, Dudley J, Nei M and Kumar S (2007). MEGA 4: Molecular evolutionary genetics analysis (MEGA) software version 4.0. Mol. Biol. Evol. 24: 1596-1599.

van der Bank H, van der Bank M and van Wyk B (2001). A review of the use of allozyme electrophoresis in plant systematic. Biochem. Syst. Ecol. 29: 469-483.

Wang BY and Ruan ZY (2012). Genetic diversity and differentiation in Camellia reticulata (Theaceae) polyploid complex revealed by ISSR and ploidy. Genet. Mol. Res. 1: 503-511.

Wang XM, Hou XQ, Zhang YQ, Yang R, et al. (2012). Genetic diversity of the endemic and medicinally important plant Rheum officinale as revealed by inter-simple sequence repeat (ISSR) markers. Int. J. Mol. Sci. 13: 3900-3915.

Wang ZY, Liao L, Yuan, XJ, Guo HL, et al. (2013). Genetic diversity analysis of Cynodon dactylon (bermudagrass) accessions and cultivars from different countries based on ISSR and SSR markers. Biochem. Syst. Ecol. 46: 108-115.

Wolfe AD and Randle CP (2001). Relationships within and among species of the holoparasitic genus Hyobanche (Orobanchaceae) inferred from ISSR banding patterns and nucleotide sequences. Syst. Bot. 26: 120-130.

Wu CJ, Cheng ZQ, Huang XQ, Yin SH, et al. (2004). Genetic diversity among and within populations of Oryza granulata from Yunnan of China revealed by RAPD and ISSR markers: Implications for conservation of the endangered species. Plant Sci. 167: 35-42.

Xie Q, Liu ZH, Li ZQ, Yuan ZL, et al. (2013). Analysis of the taxonomical position of Pinus tabulaeformis f. shekanensis based on RAPD markers and morphological traits. For. Res. 26: 151-155.

Yeh FC, Yang RC and Boyle TBJ (1999). POPGENE Version 1.31 Microsoft Windows-based Freeware for Population Genetic Analysis. Quick Users' Guide. University of Alberta, Edmonton.

Zhang XP, Li XH and Qiu YX (2006). Genetic diversity of the endangered species Kirengeshoma palmata (Saxifragaceae) in China. Biochem. Syst. Ecol. 34: 38-47.

Zhao F, Zhang WH and Yao XQ (2009). Study on reproductive characteristics of Pinus tabulaeformis f. shekanensis populations in Ziwuling region of the Loess Plateau. J. Northwest Agric. For. Univ. 37: 67-75.

Zheng DJ, Xie LS, Zhu JH and Zhang ZL (2012). Low genetic diversity and local adaptive divergence of Dracaena cambodiana (Liliaceae) populations associated with historical population bottlenecks and natural selection: An endangered long-lived tree endemic to Hainan Island. China Plant Biol. 14: 828-838.

Zhu ZC (1987). Preliminary analysis on the formation of a less-resin ecotype of Pinus tabulaeformis Carr. Shannxi For. Sci. 4: 1-2.

Zietkiewicz E, Rafalski A and Labuda D (1994). Genome fingerprinting by simple sequence repeat (SSR) anchored polymerase chain reaction amplification. Genomics 20: 176-183. 